\title{
Mutants of Escherichia coli O9:K30 with Altered Synthesis and Expression of the Capsular K30 Antigen
}

\author{
By CHRIS WHITFIELD, * GARY SCHOENHALS AND LORI GRAHAM \\ Department of Microbiology, College of Biological Sciences, University of Guelph, Guelph, \\ Ontario NIG 2W1, Canada
}

(Received 26 June 1989; accepted 30 June 1989)

\begin{abstract}
Escherichia coli $\mathrm{K} 30$ produces a thermostable group I capsular polysaccharide. Two classes of mutants were isolated with defects in the synthesis or expression of capsule. The most common mutant phenotype was acapsular $\left(\mathrm{K}^{-}\right)$, with no $\mathrm{K}$-antigen synthesized. A second class of mutants, termed $\mathrm{Ki}$ or intermediate forms, produced colonies which were indistinguishable from those of acapsular forms yet $\mathrm{K}$-antigenicity was expressed. Previous studies had demonstrated that $E$. coli strains that produce K30 antigen synthesize a lipopolysaccharide (LPS) fraction that is recognised by monoclonal antibodies against the K30 antigen. Synthesis of this LPS fraction was not affected in $\mathrm{Ki}$ forms. The results of morphological examination, LPS analysis and phage sensitivity studies are consistent with the interpretation that the defect in $\mathrm{Ki}$ strains results from an inability to polymerize the K30 antigen. Using plasmid pULB113 (RP4 : : mini-Mu), mutations resulting in both $\mathrm{K}^{-}$and $\mathrm{Ki}$ phenotypes were localized near the his region of the chromosome.
\end{abstract}

\section{INTRODUCTION}

The capsular antigens, or K-antigens, of Escherichia coli consist of polysaccharides which can be subdivided into two groups based on chemical and physical properties (Jann \& Jann, 1987).

Group II capsular polysaccharides (CPS) include those K-antigens originally designated thermolabile (Ørskov et al., 1977). These polysaccharides structurally resemble the CPS of Neisseria meningitidis and Haemophilus influenzae. Some CPS from group II E. coli and $N$. meningitidis contain a phosphatidic acid residue at the reducing terminus (Gotschlich et al., 1981 ; Schmidt \& Jann, 1982) and this lipid may play a role in maintenance of the capsular layer at the cell surface, through hydrophobic interactions (Jann \& Jann, 1987).

The group I CPS of $E$. coli differ fundamentally from group II in that they are thermostable and often closely resemble structures found in Klebsiella CPS. At least some group I CPS terminate in lipid A-core, indicating that these $\mathrm{K}$-antigens may be expressed on the cell surface as an acidic lipopolysaccharide (LPS) (Jann \& Jann, 1987). We have recently described an LPS fraction from $E$. coli $\mathrm{K} 30$ (group I CPS), which migrates near the lipid A-core in SDS-PAGE and appears to react with monoclonal antibodies directed against the K30 CPS (Homonylo et al., 1988). These results are consistent with the interpretation that lipid A-core is involved in presenting at least some $\mathrm{K}$-antigenicity at the cell surface in $E$. coli $\mathrm{K} 30$, and support previous reports of an LPS fraction consisting of a lipid A-core bearing a single repeating unit of $\mathrm{K}$-antigen in E. coli K30 (Jann \& Jann, 1977).

The genes for the group II $E$. coli CPS map at a locus termed kps (Silver et al., 1984; Vimr et $a l ., 1989$ ), formerly kpsA (Ørskov \& Nyman, 1974), which is located near ser $A$ on the $E$. coli linkage map. In contrast, the genetic determinants for group I CPS have been reported to be

\footnotetext{
Abbreviations: CPS, capsular polysaccharide; LPS, lipopolysaccharide; KDO, 2-keto-3-deoxyoctulosonic acid (3-deoxy-D-manno-octulosonic acid); mAb, monoclonal antibody; MNNG, $N$-methyl- $N^{\prime}$-nitro- $N$ nitrosoguanidine.
} 
organized similarly to those for Salmonella LPS O-antigen (Mäkelä \& Stocker, 1984). The products of CPS biosynthesis genes linked to his and $r f b$ (O-antigen) are responsible for the synthesis and assembly of the CPS repeating unit (Schmidt et al., 1977). A second locus, tentatively placed near $\operatorname{tr}$, has been suggested to encode a putative CPS polymerase, analogous to the O-antigen polymerase ( $r f c$ gene) in Salmonella (Schmidt et al., 1977). Mutations in the putative polymerase would yield intermediate or $\mathrm{Ki}$ forms which express $\mathrm{K}$-antigenicity but lack the full capsular layer which masks underlying structures in wild-type bacteria. Studies in this laboratory have demonstrated that RP4 : : mini-Mu mediated transfer of the his region from $E$. coli $\mathrm{K} 30$ to an unencapsulated $E$. coli $\mathrm{K} 12$ recipient was sufficient for synthesis of a 'full' $\mathrm{K} 30$ capsule (Laakso et al., 1988).

We are interested in the synthesis and assembly of group I $E$. coli CPS using $E$. coli $\mathrm{K} 30$ as a prototype system. The objective of the studies presented here was to isolate and characterize mutants altered in the synthesis and expression of the $\mathrm{K} 30$ antigen, in an attempt to define the range of CPS mutant phenotypes and to resolve the apparently contradictory results regarding the distribution of $\mathrm{K}$-antigen loci. To differentiate the group I CPS biosynthesis genes from those of group II ( $k p s)$ in $E$. coli, we propose the designation $k s t$ ( $K$-antigen, thermoSTable) for group I.

\section{METHODS}

Bacterial strains and growth conditions. The bacterial strains and plasmids used in this study are given in Table 1. Escherichia coli strains E69 and W6930 have been described elsewhere (Homonylo et al., 1988). Bacterial strains were routinely grown in Luria broth (LB) medium supplemented with $1.5 \%(w / v)$ agar for plates. The antibiotics ampicillin (Ap; $100 \mu \mathrm{g} \mathrm{ml}^{-1}$ final concentration), kanamycin $\left(\mathrm{Km} ; 50 \mu \mathrm{g} \mathrm{ml}^{-1}\right.$ ), tetracycline (Tc; $\left.15 \mu \mathrm{g} \mathrm{ml}^{-1}\right)$ and streptomycin (Str; $100 \mu \mathrm{g} \mathrm{ml}^{-1}$ ) were obtained from Sigma. For conjugation experiments, M9 minimal medium (Gibco) was supplemented with $0.2 \% \mathrm{D}$-glucose and the appropriate antibiotics. Amino acids were obtained from Sigma and included at final concentrations of $40 \mu \mathrm{g}$ whenever appropriate. All incubations were at $37^{\circ} \mathrm{C}$.

Determination of $O 9$ and $K 30$ antigen expression. The presence of capsule was determined by susceptibility to coliphage K30 (Whitfield \& Lam, 1986), and by agglutination using K30-capsule-specific monoclonal antibody (mAb) 4-15A (Homonylo et al., 1988). Similarly, bacteriophage 09-1 and Difco anti-O9 antibody provided tests for the presence of the O9 LPS (Homonylo et al., 1988).

Isolation of mutants. The mutant strains reported in this study were obtained either as spontaneous mutants, or following mutagenesis with $N$-methyl- $N^{\prime}$-nitro- $N$-nitrosoguanidine (MNNG) (Miller, 1972). The isolation of spontaneous mutants deficient in either $\mathrm{K} 30$ or $\mathrm{O} 9$ antigens, which occurred at relatively low frequency, was facilitated by the use of coliphages K30 and 09-1, respectively. LB plates were inoculated as lawns from overnight

\section{Table 1. Bacterial strains and plasmids used in this study}

Bacterial strain

E. coli E69

E. coli W6930

E. coli B192

E. coli $\mathrm{B} 198$

E. coli $\mathrm{B} 70$

E. coli B78

\section{Salmonella \\ typhimurium \\ SGSC82 \\ Salmonella \\ typhimurium \\ SA2876}

pULB113
Relevant

$\mathrm{O} 9: \mathrm{K} 30: \mathrm{H} 12$

O9: K30

$\mathrm{O} 9: \mathrm{K}^{-}$

$\mathrm{O}^{-}: \mathrm{K}^{-}$

O9 : ${\mathrm{K} 30 \mathrm{i}^{*}}^{*}$

$\mathrm{O}^{-}$:K30i*
Genotype or relevant properties

Prototroph, reference strain

for K30 antigen

E69 but $\mathrm{His}^{-} \mathrm{Trp}^{-} \mathrm{Lac}^{-} \mathrm{Str}^{\mathrm{R}}$

W6930; kst-1

B192; defective in O-antigen expression

W6930; kst-7

B70; defective in $\mathrm{O}$-antigen expression rfc-497 met $A 22 \operatorname{trpC} 2 \mathrm{H} 1-\mathrm{b}$ H 1-e,n,x fla-66 rps L120

[MA421(pULB113)]; metA22 metE55I trpC2 ilv-452 rpsL120 xyl-404 galE436 hsdLT6 H1-b H2-e,n,x flaA66 (pULB113)

tra ${ }^{+}$bla $^{+}(\mathrm{TEM}-2) \mathrm{Tn} l$ tet $^{+} a p h A^{+}$ (Mu3A)
Source or reference

Homonylo et al. (1988)

Homonylo et al. (1988)

Spontaneous mutant selected using coliphage K30: this study

Spontaneous mutant selected using coliphage 09-1; this study

MNNG mutagenesis; this study

Spontaneous mutant selected using coliphage $09-1$; this study

K. E. Sanderson (Department of Biological Sciences, University of Calgary, Canada)

Kadam et al. (1985)

Van Gijsegem \& Toussaint (1982)

* K30 intermediate form; see text. 
broth cultures of the appropriate parent strain. Once dry, $0.05 \mathrm{ml}$ spots of bacteriophage were applied. The plates were incubated at $37^{\circ} \mathrm{C}$. Mutants were picked as survivors from the zone of lysis. All survivors from lysates of coliphage $\mathrm{K} 30$ were acapsular $\left(\mathrm{K}^{-}\right)$. Similarly, survivors from coliphage O9-1 lysates had lost the LPS O-antigen. With the higher mutation frequencies obtained using MNNG mutagenesis, acapsular mutants were picked from dilution plates based on altered colonial morphology, and no bacteriophage selection was necessary. Each mutant was then tested for $\mathrm{O} 9$ and $\mathrm{K} 30$ antigen expression.

Isolation and fractionation of LPS from E. coli B78. LPS was extracted from bacterial cells using $45 \%(\mathrm{w} / \mathrm{v})$ aqueous phenol at $65^{\circ} \mathrm{C}$ (Westphal \& Jann, 1965). The LPS was collected by ultracentrifugation $(200000 \mathrm{~g}$ for $16 \mathrm{~h}$ ), resuspended in $10 \mathrm{mM}-\mathrm{MgCl}_{2}, 50 \mathrm{mM}$-Tris/ $\mathrm{HCl}, \mathrm{pH} 7.2$ and treated for $2 \mathrm{~h}$ at $37^{\circ} \mathrm{C}$ with $5 \mu \mathrm{g}$ RAase and DNAase $\mathrm{ml}^{-1}$ (Sigma). The sample was then treated with $5 \mu \mathrm{g}$ proteinase $\mathrm{K} \mathrm{ml}^{-1}$ (Sigma) at $50^{\circ} \mathrm{C}$ for $2 \mathrm{~h}$. The LPS was recovered by ultracentrifugation and washed twice in distilled water prior to lyophilization.

LPS was fractionated using a modification of the method described by MacIntyre $e t$ al. (1986). The purified LPS was resuspended in $3 \%(\mathrm{w} / \mathrm{v})$ sodium deoxycholate, $0.2 \mathrm{M}-\mathrm{NaCl}, 0.005 \mathrm{M}-\mathrm{EDTA}, 0.02 \mathrm{M}-\mathrm{Tris} / \mathrm{HCl}, \mathrm{pH} \mathrm{8.3.}$ Samples of LPS ( $8 \mathrm{mg}$ in $1 \mathrm{ml}$ buffer) were subjected to gel filtration on a column of Sephadex G50 Superfine $(50 \times 2.5 \mathrm{~cm})($ Pharmacia). Column equilibration and separation were done in a buffer containing $0.25 \%(\mathrm{w} / \mathrm{v})$ sodium deoxycholate, $0.2 \mathrm{M}-\mathrm{NaCl}, 0.005 \mathrm{M}$-EDTA and $0.01 \mathrm{M}$-Tris/ $\mathrm{HCl}, \mathrm{pH} 8 \cdot 0$. Fractions $(2.5 \mathrm{ml})$ were collected and analysed for 2-keto-3-deoxyoctulosonic acid (KDO) content (Karkhanis et al., 1978). LPS-containing fractions were indicated by the presence of KDO and were examined by SDS-PAGE. Fractions containing homogeneous LPS species were pooled, exhaustively dialysed against distilled water and lyophilized.

LPS analysis. This was done by SDS-PAGE. Except where purified LPS was examined, routine samples were prepared by the SDS-proteinase K method (Hitchcock \& Brown, 1983) and the SDS-PAGE system was that described by Darveau \& Hancock (1983). The silver staining procedure of Tsai \& Frasch (1982) was used to visualize electrophoretically separated LPS.

Immunoelectrophoresis. Rocket electrophoresis was done using $1 \%(\mathrm{w} / \mathrm{v}$ ) agarose (Seakem ME; Mandel Scientific, Guelph, Ontario, Canada) gels and a buffer system containing 0.024 M-barbituric acid C IV, 0.00035 Mcalcium lactate and $0.073 \mathrm{M}$ Tris-base, pH 8.6 (Lam et al., 1983). Ascites fluid containing mAb 4-15A was incorporated into the gel at $0.05 \mathrm{ml}(\mathrm{ml} \mathrm{gel})^{-1}$. Electrophoresis was done at $10 \mathrm{~V} \mathrm{~cm}^{-1}$ for $3 \mathrm{~h}$. After electrophoresis, gels were washed, pressed, dried and stained with Coomassie brilliant blue as described by Weeke (1973).

Examination of bacterial morphology by freeze substitution and electron microscopy. The capsule morphology of $E$. coli mutants was examined using freeze substitution, a procedure which retains structural aspects of the highly hydrated CPS, without a requirement for antibody stabilization. A full description of the technique will be published subsequently. Briefly, bacteria were grown overnight in LB, harvested by centrifugation, resuspended and layered onto Millipore filters. The immobilized bacteria were frozen by plunging into liquid propane at $-195^{\circ} \mathrm{C}$. Frozen samples were fixed and dehydrated at $-75^{\circ} \mathrm{C}$, with $2 \%(\mathrm{w} / \mathrm{v})$ osmium tetraoxide and $2 \%(\mathrm{w} / \mathrm{v})$ uranyl acetate in anhydrous acetone. After $2 \mathrm{~d}$, samples were allowed to reach room temperature and were washed using anhydrous acetone. The samples were then infiltrated overnight with $1: 1(\mathrm{v} / \mathrm{v})$ acetone/Epon 812 (Can EM) and embedded in Epon 812. Sections were post-stained with uranyl acetate and lead citrate before examination using a Philips EM300 electron microscope, operating at $60 \mathrm{kV}$.

Preparation of colloidal gold markers. Colloidal gold particles with an average diameter of $12.5 \mathrm{~nm}$ were coupled to diaminoethane-derivatized dextran as described by Lam et al. (1987). The colloidal gold was then coupled to Protein A (Boehringer Mannheim) using the method of Hicks \& Molday (1986).

Colloidal gold labelling. Copper grids (100 mesh) were coated with carbon and Formvar. Prior to use, each grid was treated with $0.1 \%$ peptone as a wetting agent. Bacterial cells were scraped with a sterile toothpick from an overnight plate culture and resuspended in phosphate-buffered saline (PBS; Voller et al., 1986). Bacteria in a drop of PBS were added to the grids and allowed to dry. The grids were then blocked for $15 \mathrm{~min}$ using BSA $(3 \%$, w/v, in PBS) and washed by inverting on successive drops of PBS. mAb 4-15A (0.05 ml) was added to the grid and incubated in a moist chamber for $30 \mathrm{~min}$ at room temperature. Excess antibody was removed by washing extensively over drops of PBS containing BSA $(0.5 \%, \mathrm{w} / \mathrm{v})$. Since mAb 4-15A is an IgM antibody, a second antibody $(0.5 \mathrm{ml}$ goat anti-mouse IgM; Cappel Worthington Biochemicals) was used to provide the IgG for protein A binding. After $30 \mathrm{~min}$ incubation at room temperature, the washing procedure was repeated. The protein-A-coupled gold marker $(0.08 \mathrm{ml})$ was added and allowed to react at room temperature for $30 \mathrm{~min}$. The grid was again extensively washed.

Negative staining and electron microscopy. Samples were negatively stained in $0.5 \%(\mathrm{w} / \mathrm{v})$ ammonium molybdate, $\mathrm{pH} 7 \cdot 0$, by inverting the grids on a drop of stain for $5 \mathrm{~s}$. Excess stain was removed by a filter paper wedge. The grids were examined in a Philips EM300 transmission electron microscope operating at $60 \mathrm{kV}$.

Conjugation experiments. Transfer of pULB1 13 (RP4 : : mini-Mu) was done as described by Kadam et al. (1985) and involved incubation on LB plates of $0.5 \mathrm{ml}$ portions of overnight LB cultures of donor and recipient. After $18 \mathrm{~h}$ incubation at $37^{\circ} \mathrm{C}$, conjugation mixtures were collected, diluted in PBS, and spread on appropriate selective media. Strains carrying pULB 113 were selected and maintained on media containing Ap, Tc and $\mathrm{Km}$. 
Table 2. Phenotypes of cell surface polysaccharide mutants derived from E. coli $09: K 30$

$\begin{array}{ll}\begin{array}{l}E . \text { coli } \\ \text { strain }\end{array} & \text { Serotype } \\ \text { W6930 } & \mathrm{K} 30: \mathrm{O} 9 \\ \text { B192 } & \mathrm{K}^{-}: \mathrm{O}^{-} \\ \text {B198 } & \mathrm{K}^{-}: \mathrm{O}^{-} \\ \text {B70 } & \mathrm{Ki}: \mathrm{O9}^{-} \\ \text {B78 } & \mathrm{Ki}: \mathrm{O}^{-}\end{array}$

$\begin{array}{cr}\text { K30 } & \text { O9 } \\ + & - \\ - & + \\ - & - \\ + & + \\ + & -\end{array}$

\begin{tabular}{|c|c|}
\hline \multicolumn{2}{|c|}{$\begin{array}{l}\text { Agglutination in } \\
\text { specific antibody }\end{array}$} \\
\hline K30 & O9 \\
\hline+ & - \\
\hline- & + \\
\hline- & \\
\hline+ & - \\
\hline+ & \\
\hline
\end{tabular}

\section{RESULTS}

Isolation of capsule-defective mutants

Spontaneous mutants were isolated from coliphage-K30-treated cultures of E. coli W6930 with frequencies in the order of $10^{-4}$ to $10^{-5}$. These frequencies are similar to those reported for E. coli K1 CPS mutants (Vimr \& Troy, 1985). Mutagenesis using MNNG increased this frequency by 10 - to 100 -fold. Approximately 250 independent capsule-defective mutants have been isolated and all were easily distinguished from the $\mathrm{K} 30^{+}$wild-type based on colony morphology; the wild-type strains produced larger, opaque colonies whereas colonies from capsule-defective mutants were smaller and transparent.

The mutants were examined for the presence of the $\mathrm{O} 9$ and $\mathrm{K} 30$ antigens. The majority of mutants (242 of 250), including all (180) spontaneous mutants isolated using coliphage K30, demonstrated typical acapsular $\left(\mathrm{K}^{-}\right)$phenotypes. In these strains, represented by $E$. coli $\mathrm{B} 192$, the LPS O9 antigen was exposed to anti-O9 antibody and coliphage O9-1 (Table 2). In E. coli W6930 $\left(\mathrm{K}^{3} 0^{+}\right)$, the capsule layer effectively masked the underlying LPS. Only six mutants simultaneously lost both $\mathrm{O} 9$ and $\mathrm{K} 30$ antigens.

Among 70 mutants isolated following MNNG mutagenesis, eight strains were identified with phenotypes expected of $\mathrm{Ki}$, or intermediate forms (Schmidt et al., 1977). This phenotype is represented by $E$. coli B70. Typically, these mutants reacted with probes directed against both O9 and K30 antigens (Table 2), indicating exposure of both antigens on the cell surface. Colonies of $\mathrm{K}^{-}$and $\mathrm{Ki}$ forms could not be distinguished visibly.

\section{Morphological examination of capsule-defective mutants}

To confirm the absence of a capsule, mutant strains were freeze-substituted and examined by electron microscopy (Fig. 1). A fibrillar layer extending 50-100 $\mathrm{nm}$ from the surface of the outer

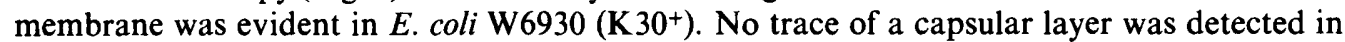
$E$. coli $\mathrm{B} 192\left(\mathrm{~K}^{-}\right)$and $E$. coli $\mathrm{B} 70(\mathrm{Ki})$; the morphologies of these mutants were indistinguishable.

\section{LPS profiles in capsule-defective mutants}

Previously, we have shown the presence of a unique LPS fraction in $\mathrm{K}^{3} 0^{+}$strains which is recognized by mAb 4-15A, specific for K30 polysaccharide (Homonylo et al., 1988). Results of SDS-PAGE analysis of capsule-defective strains (Fig. 2) illustrated that this LPS fraction (indicated by the arrow) was present in $\mathrm{Ki}$ strains (lane 4), and confirmed its absence in $\mathrm{K}^{-}$ strains (lane 3). This LPS fraction was also present in E. coli B78, a Ki derivative lacking the O9 antigen (lane 5).

For reference, the LPS from E. coli B198 $\left(\mathrm{O}^{-}: \mathrm{K}^{-}\right)$was included (lane 1) to illustrate the migration of rough lipid A-core. All the $E$. coli strains examined contained some rough lipid Acore. Lane 6 shows the migration of LPS from a Salmonella typhimurium $r f c$ mutant; in this strain, the lipid A-core is substituted with a single repeating unit of $\mathrm{O}$-antigen, due to a defect in the O-antigen polymerase (Mäkelä \& Stocker, 1984). 

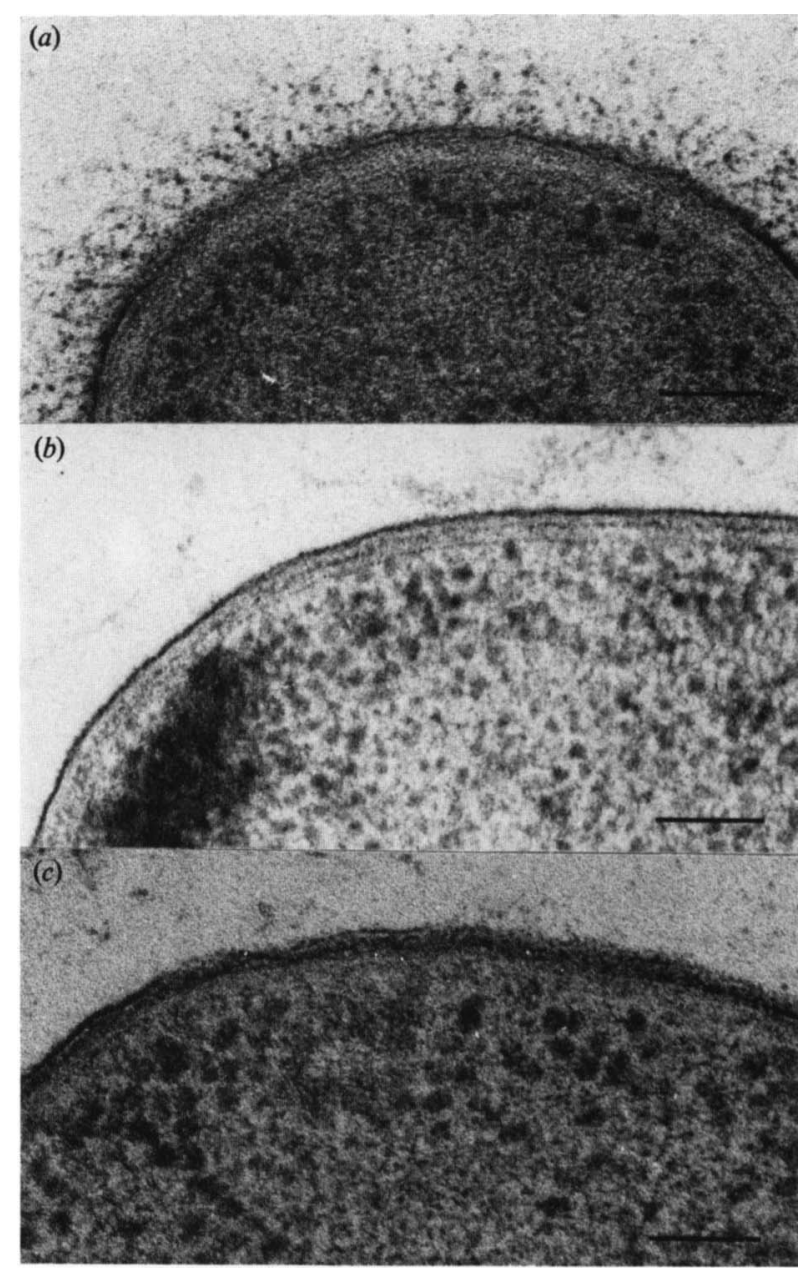

Fig. 1. Morphological examination of $E$. coli K30 CPS mutants, using freeze substitution. (a) $E$. coli W6930 (O9:K30); (b) E. coli B192 (O9:K), a typical acapsular strain; (c) E. coli B70 (O9:Ki), a Ki representative. Bar, $100 \mathrm{~nm}$.

\section{Immunoreactivity and surface expression of lipid A-core-associated $K$-antigen}

The interaction of $\mathrm{mAb} 4-15 \mathrm{~A}$ with the LPS-associated $\mathrm{K}$-antigen fraction from the wild-type E. coli $\mathrm{O} 9$ : $\mathrm{K} 30$ could not be demonstrated by Western immunoblotting (Homonylo et al., 1988). This was also true for the material in the Ki mutant $E$. coli B78 (results not shown). The reasons for the lack of reaction remain unclear. To demonstrate that the unique fraction visualized in SDS-PAGE profiles of $E$. coli B78 (Ki) LPS was responsible for the reaction with mAb 4-15A, this fraction was purified to homogeneity by gel-filtration chromatography on Sephadex G50. The SDS-PAGE profile of the purified material is shown in Fig. 3(a). The samples were examined by rocket immunoelectrophoresis using mAb 4-15A (Fig. 3b). As found previously using the $E$. coli $\mathrm{K} 30$ parental strain, only the lipid A-core fraction unique to $\mathrm{K}$ and $\mathrm{Ki}$ strains reacted with the antibody. No reaction was obtained with other purified lipid A-core fractions. Also, no reaction was obtained with any column fraction lacking KDO (results not shown).

Surface expression of this $\mathrm{K}$-antigen in $\mathrm{Ki}$ strains was indicated by the positive results of agglutination tests using mAb 4-15A. To directly confirm the surface exposure of the antigen, whole cells were labelled with colloidal gold markers coupled to protein A. As shown in Fig. $4(a)$, Ki mutant $E$. coli B78 showed extensive labelling. The colloidal gold probe was randomly 


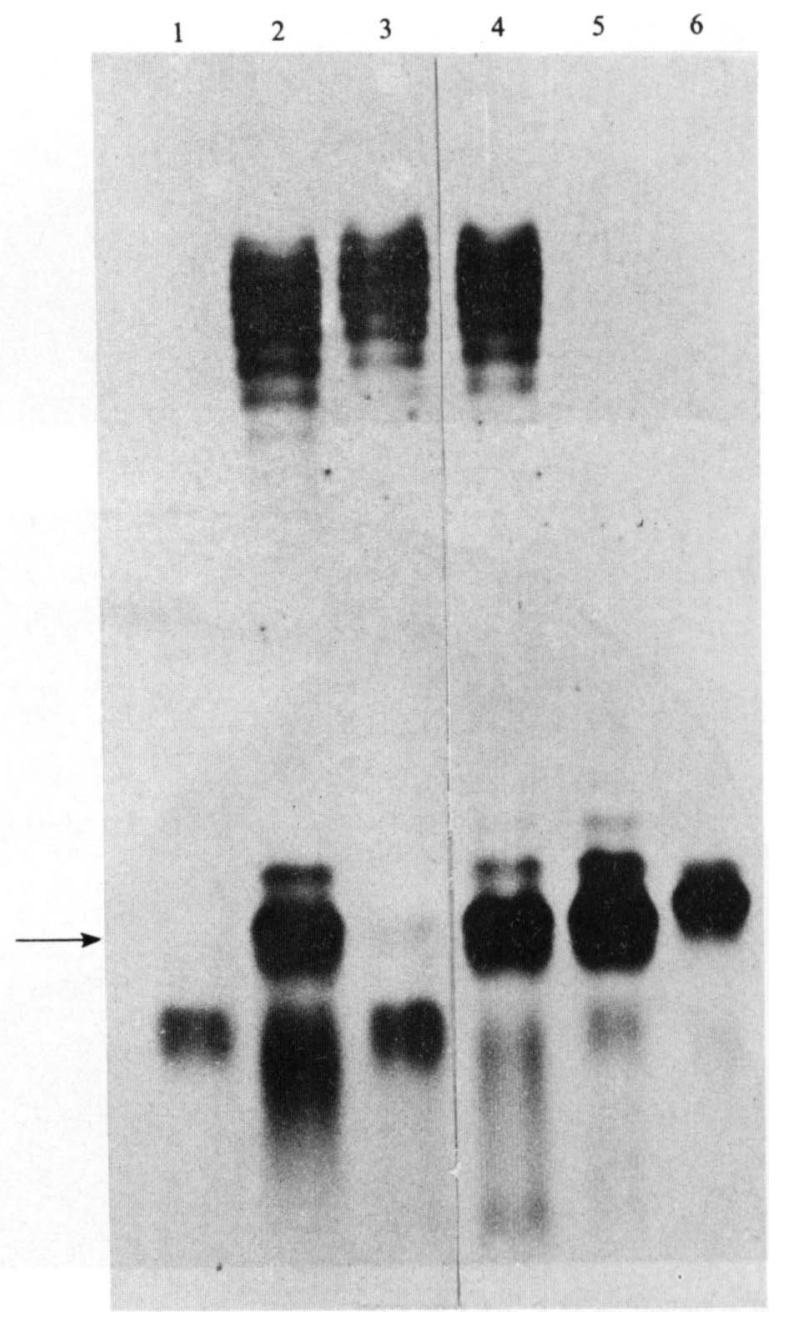

Fig. 2. SDS-PAGE analysis of LPS in E. coli $\mathrm{K}$-antigen and O-antigen mutants. Lane 1, E. coli B198 $\left(\mathrm{O}^{-}: \mathrm{K}^{-}\right)$; lane $2, E$. coli $\mathrm{W} 6930(\mathrm{O} 9: \mathrm{K} 30)$; lane 3, E. coli B192 $\left(\mathrm{O} 9: \mathrm{K}^{-}\right)$; lane 4, E. coli B70 $(\mathrm{O} 9: \mathrm{Ki})$; lane $5, E$. coli $\mathrm{B} 78\left(\mathrm{O}^{-}: \mathrm{Ki}\right)$; lane $6, S$. typhimurium SA2876, an $r f c$ mutant. The arrow indicates migration of an LPS fraction present only in $\mathrm{K}^{+}$and $\mathrm{Ki}$ strains.

distributed over the entire surface. Identical labelling was obtained using E. coli B70 (O9:Ki) and $E$. coli W6930 (O9:K30) (results not shown). The lack of any detectable differences between the labelling of $\mathrm{Ki}$ and authentic $\mathrm{K} 30$ strains probably reflects the collapse of the wild-type capsular layer present in the surface of the cell. This would result from dehydration prior to negative staining. No labelling occurred if either the first or second antibody steps were omitted. As a further control E. coli B192 (O9: $\left.\mathrm{K}^{-}\right)$was used. As shown in Fig. 4(b), the acapsular strain was not labelled.

\section{Preliminary mapping of E. coli K30 CPS mutations}

To determine the approximate location of the K30 biosynthetic genes, we have previously used R-prime plasmids generated by pULB113 (Laakso et al., 1988). Plasmid pULB113 contains a Mu3A (mini-Mu) which carries a functional transposase but lacks lethal functions. R-Prime plasmids are generated by random chromosomal integration and excision and can be transferred by conjugation (Van Gijsegem \& Toussaint, 1982). Plasmid pULB113 was 
(a)

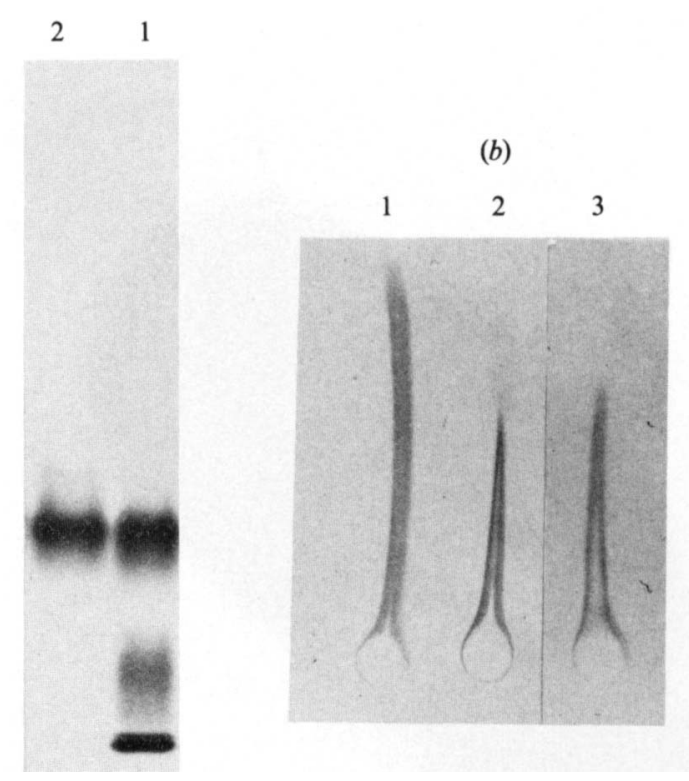

Fig. 3. Rocket immunoelectrophoresis of the purified LPS fractions expressing K 30 antigenicity in $E$. coli $\mathrm{B} 78(\mathrm{Ki})$. (a) SDS-PAGE profile of the K30-antigenic fractions: lane 1, $E$. coli B78 unfractionated LPS; lane 2, LPS-associated K-antigenic fraction. (b) Analysis of the reaction of the LPS samples with the K-antigen-specific mAb 4-15A : lane 1, control with purified high molecular mass K30 CPS; lane 2, $E$. coli B78 unfractionated LPS; lane 3, LPS-associated K-antigenic fraction. (10 $\mu \mathrm{g}$ of each antigen was analysed.)

\section{Table 3. Mapping of K30 defects using R-prime plasmids}

Figures in parentheses are percentage values

Recipient

strain

$\mathrm{B} 70(\mathrm{Ki}: \mathrm{O})$

$\mathrm{B} 192\left(\mathrm{~K}^{-}:\right.$O9)

$\overbrace{\text { Tested }}^{\text {Phenotype of } \mathrm{His}^{+} \text {transconjugants }} \mathrm{Ki}_{\mathrm{K}^{+}}$

289

241

$\begin{aligned} 15(5) & 274(95) \\ 6(2) & 235(98)\end{aligned}$

transferred to $E$. coli $\mathrm{E} 69$ to produce the source of R-prime plasmids. The R-primes were then transferred to either $E$. coli $\mathrm{Ki}$ or $\mathrm{K}^{-}$mutants. Following selection for restoration of the $\mathrm{His}^{-}$or $\mathrm{Trp}^{-}$defects, transconjugants were tested for the presence of K30 capsule. Encapsulation was assessed by the masking of the LPS receptor for coliphage 09-1, by colony morphology, and was confirmed by electron microscopy. As shown in Table 3, both $\mathrm{K}^{-}$and $\mathrm{Ki}$ defects were complemented in $\mathrm{His}^{+}$transconjugants. No complementation occurred in $\mathrm{Trp}^{+}$transconjugants. Only results obtained with $E$. coli $\mathrm{B} 70$ and $E$. coli $\mathrm{B} 192$ are shown; other strains with each phenotype gave identical results.

\section{DISCUSSION}

Two CPS mutant phenotypes were identified. The first and most prevalent was the true acapsular form with no capsular layer or $\mathrm{K}$-antigen. The less frequent mutant class was the $\mathrm{Ki}$ strains which also produced no capsular layer but did express $\mathrm{K}$-antigenicity. The $\mathrm{Ki}$ mutants were not detected among spontaneous mutants but approximately $10 \%(8$ of 70$)$ of the MNNGderived mutants belonged to this class. In retrospect, this observation is easily explained. In 
(a)
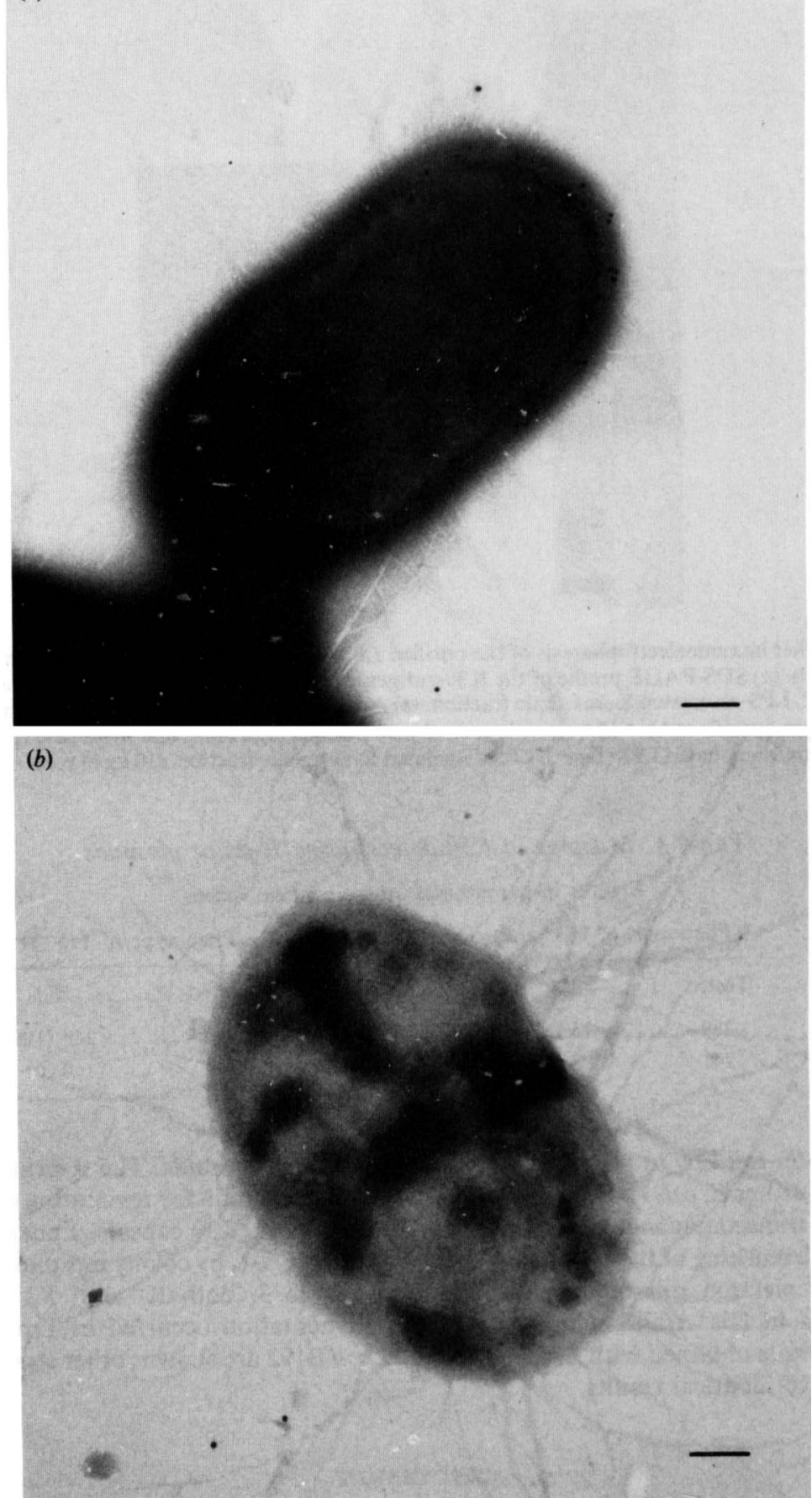

Fig. 4. Colloidal gold labelling of surface-exposed K-antigen in E. coli B78 (Ki). (a) Surface labelling of $E$. coli $\mathrm{B} 78 ;(b) E$. coli $\mathrm{B} 192\left(\mathrm{~K}^{-}\right)$used as a negative control to demonstrate the specificity of the labelling procedure. Bar, $200 \mathrm{~nm}$. 
order to isolate spontaneous mutants at a frequency of $10^{-4}$ to $10^{-5}$, coliphage $\mathrm{K} 30$ was used to lyse wild-type encapsulated bacteria and enrich for mutants in the population. Surprisingly, coliphage $\mathrm{K} 30$ also infected $\mathrm{Ki}$ strains, suggesting that the bacteriophage does not have an absolute requirement for a wild-type capsule as a primary receptor. As a result, the bacteriophage selection which was effective for isolation of $\mathrm{K}^{-}$mutants removed any spontaneous $\mathrm{Ki}$ mutants from the population.

The $\mathrm{K}$-antigenic fraction in $\mathrm{Ki}$ strains was surface expressed. However, morphological studies and exposure of LPS O-antigen demonstrated the lack of a wild-type capsular layer in $\mathrm{Ki}$ mutants. Other techniques commonly used to demonstrate capsules, such as cationized ferritin (Laakso et al., 1988) or antibody stabilization (Whitfield et al., 1984) also failed to show evidence of high molecular mass K-antigen (results not shown), as did the technique used to prepare high molecular mass K30 polysaccharide described by Hungerer et al. (1967). Based on rocket immunoelectrophoresis of LPS fractions from $E$. coli B78, it appears that the only source of Kantigenicity in the $\mathrm{Ki}$ strains is the LPS lipid-A-core-associated fraction. In addition to high molecular mass $\mathrm{K} 30$ antigen, wild-type strains also produced a low molecular mass LPSassociated K-antigen fraction (Homonylo et al., 1988), with a migration in SDS-PAGE identical to that from $\mathrm{Ki}$ strains. This result suggests that synthesis of the $\mathrm{K}$-antigenic fraction seen in isolation in $\mathrm{Ki}$ strains occurs under normal conditions, rather than resulting from an artifact induced by MNNG mutagenesis. A CPS polymerase defect, as proposed by Schmidt et al. (1977) would account for the Ki phenotype. The migration of the K30 antigenic LPS fraction in SDS-PAGE was consistent with this interpretation, using LPS from a $S$. typhimurium $r f c$ mutant for comparison purposes.

It has not been possible to identify a lipid A-core moiety at the terminus of a high molecular mass K30 CPS chain. This may reflect the technical difficulties associated with isolating the small amount of lipid A-core present relative to the large mass of CPS. Little is known in general about the precise mechanism(s) involved in linkage of capsules to the bacterial cell surface. $E$. coli may simultaneously express both high and low molecular mass K30 antigens, with only the low molecular mass form being associated with lipid A-core.

The interrelationship between $\mathrm{O}$ - and $\mathrm{K}$-antigen expression in strains bearing group I CPS remains unclear. Some enzymes may be shared between the two biosynthetic pathways. An example would be GDP-mannose pyrophosphorylase which is involved in the generation of GDP-mannose precursor for mannose residues in both O9 (Prehm et al., 1976) and K30 antigen (Chakraborty et al., 1980). We have isolated only six mutants (from a total of 250) which have simultaneously lost both $\mathrm{O} 9$ and K30 antigens. This would suggest that the number of shared biosynthetic enzymes is small. It has been proposed that synthesis of the group I CPS is determined by genes of the $r f b$ cluster (Jann \& Jann, 1987). Although the O- and K-antigens appear closely linked (Laakso et al., 1988; Schmidt et al., 1977), there is no direct evidence to suggest that they form a single gene cluster. Indeed, from the mutations described here, it is clear that both the 09 and $\mathrm{K} 30$ antigens can be expressed independently of one another. It is therefore reasonable to retain the $r f b$ designation for genes involved in expression of the $\mathrm{O} 9$ antigen, which has been historically considered as an LPS O-antigen. To differentiate genes whose function leads specifically to the expression of the K30 antigen, we have suggested the designation $k s t(K-$ antigen, thermoSTable). This designation also distinguishes group I CPS from group II CPS (kps) loci.

Plasmid pULB113 (RP4 : : mini-Mu) provides a genetic tool for $E$. coli strains which are not amenable to other classical genetic approaches. In previous studies, we have demonstrated that transfer of the his region from $E$. coli $\mathrm{O} 9: \mathrm{K} 30$ donors to $E$. coli $\mathrm{K} 12$ recipients yielded transconjugants with capsules which were morphologically indistinguishable from that of the donor (Laakso et al., 1988). These experiments did not rule out the possibility that some unlinked CPS functions (such as a putative polymerase function) were provided by the recipient $E$. coli strain. Complementation studies presented here extend those observations and support the conclusion that all the necessary genetic determinants for K30 CPS expression, defined by mutations, are linked to his. The number of gene defects required to give the $\mathrm{Ki}$ phenotype is 
presently unknown. The differences obtained in these studies and the earlier results of Schmidt et al. (1977) are not clear.

The description of CPS phenotypes in capsule-defective mutants of $E$. coli $\mathrm{K} 30$ will now facilitate a detailed analysis of the K30 biosynthetic genes.

This work was supported by grants to C. W. from the Medical Research Council of Canada (MA-9623). The authors gratefully acknowledge the technical assistance in LPS fractionation provided by $\mathrm{Mr}$ B. Clarke. Electron microscopy was performed at the NSERC Regional STEM Facility in this department and the assistance of Dr T. J. Beveridge and Mr R. Harris is gratefully acknowledged. The authors are grateful to Dr I. Ørskov and Dr K. E. Sanderson who kindly supplied bacterial strains.

\section{REFERENCES}

Chakraborty, A. K., Friebolin, H. \& Stirm, S. (1980). Primary structure of the Escherichia coli serotype K30 capsular polysaccharide. Journal of Bacteriology 141, 971-972.

Darveau, R. P. \& Hancock, R. E. W. (1983). Procedure for isolation of bacterial lipopolysaccharides from both smooth and rough Pseudomonas aeruginosa and Salmonella typhimurium. Journal of Bacteriology 155, 831-838.

Gotschlich, E. C., Fraser, B. A., Nishimura, O., RobBins, J. B. \& LiU, T. Y. (1981). Lipid on capsular polysaccharides of Gram-negative bacteria. Journal of Biological Chemistry 256, 8915-8921.

Hicks, D. \& Molday, R. S. (1986). Differential immunogold-dextran labeling of bovine and frog rod and cone cells using monoclonal antibodies against bovine rhodopsin. Experimental Eye Research 42, 55-71.

HitchCock, P. J. \& BRown, T. (1983). Morphological heterogeneity among Salmonella lipopolysaccharide types in silver-stained polyacrylamide gels. Journal of Bacteriology 154, 269-277.

Homonylo, M. K., Wilmot, S. J., LAM, J. S., MacDonald, L. A. \& Whitfield, C. (1988). Monoclonal antibodies against the capsular $\mathrm{K}$ antigen of Escherichia coli $(\mathrm{O} 9: \mathrm{K} 30(\mathrm{~A}): \mathrm{H} 12)$ : characterisation and use in analysis of $K$ antigen organisation on the cell surface. Canadian Journal of Microbiology 34, 1159-1165.

HuNGerer, D., JANN, K., JANN, B., ØrSkov, F. \& ØrSKov, I. (1967). Immunochemistry of $K$ antigens of Escherichia coli. 4. The $\mathrm{K}$ antigen of $E$. coli $09: \mathrm{K} 30: \mathrm{H} 12$. European Journal of Biochemistry 2, $115-126$.

JANN, K. \& JANN, B. (1977). Bacterial polysaccharide antigens. In Surface Carbohydrates of the Prokaryotic Cell, pp. 247-287. Edited by I. W. Sutherland. New York: Academic Press.

JANN, K. \& JANN, B. (1987). Polysaccharide antigens of Escherichia coli. Reviews in Infectious Disease 9, S517-S526.

Kadam, S. K., Rehemtulla, A. \& Sanderson, K. E. (1985). Cloning of $r f a ~ G, B, I$ and J genes for glycosyltransferase enzymes for synthesis of the lipopolysaccharide core of Salmonella typhimurium. Journal of Bacteriology 161, 277-284.

Karkhanis, Y. D., Zeltner, J. Y., Jackson, J. J. \& CARLO, D. J. (1978). A new and improved microassay to determine 2-keto-3-deoxyoctonate in lipopolysaccharide in Gram-negative bacteria. Analytical Biochemistry 85, 595-601.
LAakso, D. H., Homonylo, M. K., Wilmot, S. J. \& Whitfield, C. (1988). Transfer and expression of the genetic determinants for $\mathrm{O}$ and $\mathrm{K}$ antigen synthesis in Escherichia coli $\mathrm{O} 9: \mathrm{K} 30$ (A) and Klebsiella $\mathrm{sp} . \mathrm{Ol}: \mathrm{K} 20$, in Escherichia coli $\mathrm{K} 12$. Canadian Journal of Microbiology 34, 987-992.

Lam, J. S., Mutharia, L. M., Hancock, R. E. W., Høiby, N., BAEK, L. \& Costerton, J. W. (1983). Immunogenicity of Pseudomonas aeruginosa outer membrane antigens examined by crossed immunoelectrophoresis. Infection and Immunity 42, 88-98.

LaM, J. S., LaM, M. Y. C., MacDonald, L. A. \& HANCOCK, R. E. W. (1987). Visualization of Pseudomonas aeruginosa $\mathrm{O}$-antigens by using a protein $\mathrm{A}$ dextran-colloidal gold conjugate with both immunoglobulin $\mathbf{G}$ and immunoglobulin $\mathbf{M}$ monoclonal antibodies. Journal of Bacteriology 169, 3531-3538.

Macintyre, S. B., LuCken, R. \& OWen, P. (1986). Smooth lipopolysaccharide is the major protective antigen for mice in the surface extract from IATS serotype 6 contributing to the polyvalent Pseudomonas aeruginosa vaccine PEV. Infection and Immunity 52, 76-84.

MÄKELÄ, P. H. \& Stocker, B. A. D. (1984). Genetics of lipopolysaccharide. In Handbook of Endotoxin, vol. I, Chemistry of Endotoxin, pp. 59-137. Edited by E. T. Reitschel. Amsterdam: Elsevier Science Publishers.

Miller, J. H. (1972). Experiments in Molecular Genetics. Cold Spring Harbour, NY: Cold Spring Harbor Laboratory.

ØRSKOV, I. \& NYMAN, K. (1974). Genetic mapping of the antigenic determinants of two polysaccharide $\mathrm{K}$ antigens, $\mathrm{K} 10$ and $\mathrm{K} 54$, in Escherichia coli. Journal of Bacteriology 120, 43-51.

ØRSKOV, I., ØRSKOV, F., JANN, B. \& JANN, K. (1977). Serology, chemistry and genetics of $\mathrm{O}$ and $\mathrm{K}$ antigens of Escherichia coli. Bacteriological Reviews 41, 667-710.

Prehm, P., JanN, B. \& JANn, K. (1976). The O9 antigen of Escherichia coli. Structure of the polysaccharide chain. European Journal of Biochemistry 67, 53-56.

SchmidT, G., JANN, B., JANN, K., ØRSKOV, I. \& ØRSKov, F. (1977). Genetic determinants of the synthesis of the polysaccharide capsular antigen K27(A) of Escherichia coli. Journal of General Microbiology 100, 355-361.

SchmidT, M. A. \& JANN, K. (1982). Phospholipid substitution of capsular $(K)$ polysaccharide antigens from Escherichia coli causing extraintestinal infections. FEMS Microbiology Letters 14, 69-74. 
Silver, R. P., VANN, W. F. \& Aaronson, W. (1984). Genetic and molecular analyses of Escherichia coli K1 antigen genes. Journal of Bacteriology 157, 568-575.

Tsai, C.-M. \& Frasch, C. E. (1982). A sensitive silver strain for detecting lipopolysaccharides in polyacrylamide gels. Analytical Biochemistry 119, 115-119.

VAN GiJsegem, F. \& Toussaint, A. (1982). Chromosome transfer and R-prime formation by an RP4::mini-Mu derivative in Escherichia coli, Salmonella typhimurium, Klebsiella pneumoniae, and Proteus mirabilis. Plasmid 7, 30-44.

VIMR, E. R. \& TROY, F. A. (1985). Regulation of sialic acid metabolism in Escherichia coli: role of $\mathrm{N}$-acylneuraminate pyruvate-lyase. Journal of Bacteriology 164, 854-860.

VimR, E. R., Aaronson, W. \& Silver, R. P. (1989). Genetic analysis of chromosomal mutations in the polysialic acid gene cluster of Escherichia coli K1. Journal of Bacteriology 171, 1106-1117.
Voller, A., Bidwell, D. E. \& Bartlett, A. (1976). Enzyme imunoassays in diagnostic medicine. Bulletins of the World Health Organization 53, 55-65.

WEEKE, B. (1973). Crossed immunoelectrophoresis. In A Manual of Quantitative Immunoelectrophoresis, pp. 47-56. Edited by N. H Axelson, J. Kroll \& B. Weeke. Oxford: Blackwell Scientific Publications.

WESTPHAL, O. \& JANN, K. (1965). Bacterial lipopolysaccharide extraction with phenol-water and further applications of the procedure. Methods in Carbohydrate Chemistry 5, 83-91.

WhITFIELD, C. \& LAM, M. (1986). Characterization of coliphage K30, a bacteriophage specific for Escherichia coli capsular serotype K30. FEMS Microbiology Letters 37, 351-355.

WhitField, C., VimR, E. R., Costeron, J. W. \& Troy, F. A. (1984). Protein synthesis is required for in vivo activation of polysialic acid capsule synthesis in Escherichia coli K1. Journal of Bacteriology 159, 321-328. 